\title{
İzmit Körfezi ve Çevresinde Bina Yoğunluk ve Sıvılaşma Yayılımının Mekânsal Analizi
}

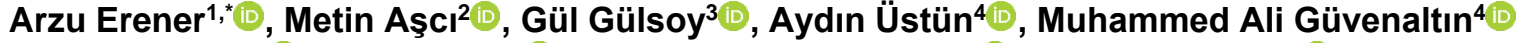 \\ Erman Şentürk ${ }^{1}$, Sefa Yalvaç ${ }^{\circ}$, Fatma Canaslan Çomut ${ }^{6}$ (D) T. Serkan Irmak ${ }^{2}$,

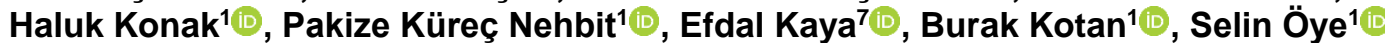

${ }^{1}$ Kocaeli Üniversitesi, Mühendislik Fakültesi, Harita Mühendisliği Bölümü,41000, Kocaeli.

${ }^{2}$ Kocaeli Üniversitesi, Mühendislik Fakültesi, Jeofizik Mühendisliği Bölümü, 41000, Kocaeli.

${ }^{3}$ Kocaeli Derince Belediyesi, Imar ve Şehircilik Müdürlüğü, 41900, Derince, Kocaeli.

${ }^{4}$ Hacettepe Üniversitesi, Mühendislik Fakültesi, Geomatik Mühendisliği Bölümü, 06100, Ankara.

${ }^{5}$ Gümüşhane Üniversitesi, Mühendislik ve Doğa Bilimleri Fakültesi, Harita Mühendisliği Bölümü, 29100, Gümüşhane.

${ }^{6}$ Başbakanlık Afet ve Acil Durum Yönetimi Başkanlığı, 20000, Denizli.

IIskenderun Teknik Üniversitesi, Harita ve Kadastro, İskenderun,31200, Hatay.

\section{Özet}

2017 yılı Aralık ayından itibaren KOÜ Harita Mühendisliği Bölümü’nün yürütücülü̈̆̈̈ ve Kocaeli Büyükşehir Belediyesi'nin desteğgi ile "Çok Bandlı InSAR ve GNSS Tekniği ile Doğu Marmara (İzmit Körfezi) Düşey Yönlü Yer Değiş̧tirmelerin İzlenmesi, Zemin Çökmeleri ile Bina Yoğunluğu ve Sivılaşma İlişkisinin Araştırılması” başlıklı ve $117 Y 155$ numaralı TÜBİTAK projesi kapsamında İzmit körfez bölgesinde risklerin tespiti için çalışmalara başlanmıştır. Bu bağlamda, proje kapsamında yapılan bina yoğunluk analizleri ve sıvılașmanın körfez bölgesi çevresindeki mekânsal dağılımı CBS ortamında bütünleșik olarak ele alınarak mekânsal dağılımları incelenmiştir. Zemindeki yüke ait bilgi çıkarımı için binaların 3. boyutu dikkate alınarak bina katlarının mekânsal dă̆ılımları mekânsal otokorelasyon çalısmaları ile irdelenmistir. Mekansal otokorelasyon analizlerinden Lokal Moran's I istatistikleri dikkate alınmıştır. Ayrıca körfez ve çevresinde görülen sivılaşma potansiyeli 0-3 m, 3-6 m, 6-9 m, 9-12m'den 33-35 m derinlikleri için olușturulmuștur. Sivılașma potansiyel eșiklerine göre, farklı derinlikler için, sivılașma değerleri kategorize edilerek sıvılaşma alanları ve riskli bölgeler tanımlanmıştır. Sonuç olarak sıvılaşma risk alanlarında bulunan bina tespitleri yapılmıştır. Çalışma; ileriye yönelik doğal afetlere karşı sürdürülebilir önlemlerin alınması, yapılaşma hızı ve yoğunluğu için önlem planlarının hazırlanması, Gölcük ve İzmit Körfez çevresinde bina ve zemin sivllaşmalarının mevcut durumunun belirlenmesi, risk taşıyan alanlarda mühendislik tedbirlerinin alınarak yapı ve can güvenliğinin sağlanması ve afet değerlendirmelerinde altlı oluşturması açısından önem arz etmektedir.

Anahtar Sözcükler

İzmit Körfezi, Sıvılaşma, Bina Kat Yoğunluğu, Mekânsal Otokorelasyon

\section{Spatial Analysis of Building Density and Liquefaction Spread in Izmit Bay and its Surroundings}

\section{Abstract}

Since December 2017, with the support of Kocaeli Metropolitan Municipality and with the leadership of Kocaeli University Geomatic Department, TÜBITAK project numbered $117 Y 155$ and titled "Monitoring of Vertical Displacements in East Marmara (Izmit Bay) with Multi-Band InSAR and GNSS Techniques, Investigation of the Relationship Between Ground Collapse and Building Density and Liquefaction" studies have been initiated to determine the risks in the Izmit Bay area. In this context, the spatial distribution of the building density analyzes and the spatial distribution of liquefaction around the gulf region were handled and integrated in the GIS environment within the scope of the project. The spatial distributions of the building floors were examined by spatial autocorrelation studies, taking into account the 3rd dimension of the buildings for the extraction of information about the load on the ground. Among the spatial autocorrelation analysis, Local Moran's I statistics were taken into consideration comparatively. In addition, the liquefaction potential observed around the bay and its surroundings is evaluated for 0-3 m, 3-6 m, 6$9 \mathrm{~m}, 9-12 \mathrm{~m}$ from 33-35 m depths. Liquefaction areas and risky areas are defined by categorizing liquefaction values for different depths according to liquefaction potential thresholds. As a result, buildings in liquefaction risk areas were determined. The study is important in terms of taking sustainable precautions against future natural disasters, preparing precaution plans for the speed and density of construction, determining the current situation of building and ground liquefaction around Gölcük and Izmit Bay, taking engineering measures in risky areas and providing building and life safety and creating a basis for disaster assessments.

$\underline{\text { Keywords }}$

Izmit Bay, Liquefaction, Building Floor Density, Spatial Autocorrelation

* Sorumlu Yazar: Tel: +90 (262) 3033253, Fax: +90 (262) 3031033

Gönderim Tarihi / Received : 09/06/2021

E-posta: arzu.erener@kocaeli.edu.tr (Erener A), masci@kocaeli.edu.tr (Aşçı M), Kabul Tarihi / Accepted

:03/11/2021 ggulsoy@derince.bel.tr (Gülsoy G), aydinustun@hacettepe.edu.tr (Üstün A) guvenaltinali@gmail.com (Güvenaltın M.A), erman.senturk@kocaeli.edu.tr (Şentürk E), sefayalvac@gmail.com (Yavaç S), Fatma.C.comut@afad.gov.tr (Canaslan Çomut F), irmakts@kocaeli.edu.tr. (Irmak T.S), hkonak@kocaeli.edu.tr (Konak H), pakize.kurec@kocaeli.edu.tr (Küreç Nehbit P), efdal.kaya@iste.edu.tr (Kaya E), bkotan19@gmail.com (Kotan B), selinoye@gmail.com (Öye S) 


\section{Giriş}

Gevşek, suya doygun durumdaki taneli zeminlerin taşıma kapasitelerini kaybederek, depremin oluşturduğu, deprem dalgalarının etkisiyle sıvı gibi davranış göstermesine zemin sıvılaşması denilmektedir. Sıvılaşma, ilk olarak 1964 yılında meydana gelen Alaska'daki 29 Nisan 1964' de (Mw=9.2) Good Friday ve 16 Haziran 1964' de Japonya'daki Niigata $(\mathrm{Ms}=7.5 \mathrm{Mw})$ depremiyle dikkat çekmiştir.

$\mathrm{Bu}$ iki depremde sıvılaşmadan dolayı yapılarda meydana gelen ani oturmalar, yanal yayılmalar, ötelenmeler, devrilmeler, taşıma gücü kayıpları oluşmuştur. Sıvılaşma ilk kez 1965 'de Arthur Cassangroid tarafından bu depremlerden sonra ortaya konulmuştur. Bu depremlerden sonra geçen 50 yıl içinde çok sayıda araştırmacı tarafindan sıvılaşma konusu incelenmiştir. Seed ve Idriss (1971) çalışmalarında 1964 yılındaki Alaska ve Niigata depreminden sonra Standart Penetrasyon Test (SPT) değerine bağlı basit bir ampirik yönteme dayalı sivılaştırma direnci hesabı geliştirmiştir. Iwasaki vd. (1982) çalışmasında zemin sıvılaşması için basit kategori ve indeks geliştirmiştir. Potansiyel indeks PL yardımıyla sıvılaşma analizi değerlendirilmesi yapılmıştır. Seed vd. (1985) tarafından enerji oranları baz alınarak SPT ile sıvılaşma ilişsisi incelenmiştir. 1971 yılında yapılan çalışma revize edilerek, sıvılaşma ilişkisini gösteren eğri iyileştirilmiştir. Ulusay vd. (2000) son depremlerde Türkiye'de gözlemlenen sıvılaşma ve Ege Bölgesi sıvılaşma potansiyelini değerlendirmiştir. Youd vd. (2001), Seed ve Idriss (1971) yllında SPT değerine bağlı basit sıvılaşma hesabını iyileştirmiş ve uygulamaya sunmuşlardır. Sönmez (2003) sıvılaşma potansiyeli olan alanların sıvılaşma duyarlılık haritalarının hazırlanması amacı ile Bursa'nın İnegöl İlçesinde sıvılaşma değerlendirmesi yaparak sıvılaşma indekslerine ait kategorilerin eksiklerinin giderilmesine yönelik araştırma yapmıştır. Çetin vd. (2004) çalışmalarında zeminlerin sıvılaşma potansiyellerini incelemiş; mevcut yükler altında zeminlerin sıvılaşıp sıvılaşmayacağını araştırmışlardır. Saygılı vd. (2007) tarafından 1999 Kocaeli ve Tayvan Depremi verileri kullanılarak Genel Regresyon Sinir Ağları (GRNN) modeli ile çalışma alanlarında sıvılaşmanın olup olmadığının anlaşılması için model çalışması yapmışlardır. Idriss ve Boulanger $(2006,2008)$ çalışmalarında sıvılaşma potansiyelini güvenlik faktörüne göre değerlendirmişlerdir.

17 Ağustos 1999 depreminin sonucu, zemin sıvllaşma potansiyelinin binalarda ne kadar büyük ölçüde hasar meydana getirebileceğini göstermiş̧tir (Barka 1999; IUÜ 1999; Demirtaş 1999; Demirtaş 2000; Efe 2000; Yüksel vd. 2000; ODTU 2000; Efe ve Demirci 2001; Aşcı vd. 2003; Bray vd. 2004; Erdik vd. 2004; Karakaş 2005; Anastasopoulos ve Gazetas 2007; Aşc1 vd. 2007; Aydan vd. 2008; Ulusay vd. 2008; Demirtaş vd. 2008). Yer altı su seviyesinin yüzeye yakın olduğu, sıkışmamış gevşek durumdaki kumlu-siltli zemin yapılarının, sıvılaşma potansiyeli yüksektir. Kuzey Anadolu Fay Hattının Marmara Denizi'nin güneyi boyunca uzandığı bölgede hem sismik aktivite çok yüksek ve hem de zemin koşulları yapılaşma için son derece elverişsizdir. Buna rağmen, 2000'li yıllardan itibaren yeni kurulan organize sanayi bölgeleri ile birlikte; bölgenin nüfus, yapılaşma ve kat yoğunluğunda hızlı bir artış yaşanmıştır. Dayanıksız ve sıvılaşma potansiyeli yüksek alüvyal sahalar üzerinde yapılaşmanın ve kat yoğunluğunun zamanla artması da, zemin deformasyon olasılığını güçlendiren unsurlardan biri olarak görülmektedir. Bu nedenle, aktif fay zonunda bulunan, sağlam olmayan alüvyal zemin üzerine kontrolsüz yapılaşmış bu gibi bölgelerin yüzey ve bina deformasyonlarının izlenmesi ve risk bölgelerinin tespiti, erken uyarı imkânlarının geliştirilebilmesi, can ve mal kaybının önlenmesi veya etkilerinin azaltılması bakımından büyük önem taşımaktadır. Bu bağlamda literatürde farklı çalışmalar yer almaktadır. Bray vd. (2017) tarafindan 17 Ağustos 1999 depreminde binaların sıvılaşma ve zemin yumuşamasına bağlı olarak oturmuş, yanal ötelenmiş, dönmüş ve sonuç olarak yıkıldığı tespit edilmiştir. Arel ve Önalp (2012) Adapazarı 1999 Marmara depreminde sıvılaşmaya bağlı hasarın büyük olduğu Sakarya nehri tarafından yaklaşık 7000 yıldır taşınarak çökelen düşük plastisiteli veya plastik olmayan ince taneli zeminlerin, tıpk1 kumlu zeminlerde olduğu gibi, yüksek sıvılaşma potansiyeli olduğunu ortaya koymuştur ve bu tür zeminlerin sıvılaşmaya bağlı oturmalara sebep olduğunu tespit etmiştir. Erken vd. (2004) tarafından depremler sırasında zeminlerin sıvılaşması ve taşıma gücü kayıpları konusu çalışılmıştır. Erken vd. (2004) bu çalışmalarında, öncelikle kum, silt ve killerin deprem yükleri altında nasıl bir davranış göstereceği üzerinde durmuşlardır. Bray ve Dashti (2014) tarafından sı̆̆ temelli binaların sıvılaşmadan kaynaklanan hareketlerini tahmin etmek için öneriler yapılmıştır. Ishihara ve Yoshimine (1992), sığ temelli bir yapıyı destekleyen toprakların sıvılaşması, önemli bina yerleşimi ve hasarı oluşturabildiği için sıvılaşma sonrası, tek boyutlu (1D) konsolidasyon oturmasını tahmin etmek için ampirik prosedürleri incelemiştir.

Binalar yer deformasyonundan kaynaklı hareketlere duyarlıdır. $\mathrm{Bu}$ nedenle sıvılaşmadan kaynaklı zemin davranışının ve üzerinde bulunan yapı bloklarının mekânsal olarak haritalanması ve gözlemlenmesi bina riskinin önceden tahmini için gereklidir. Bu bağlamda TÜBİTAK tarafından desteklenen bu çalışma kapsamında, bina yoğunluk analizleri ve sıvılaşmanın körfez bölgesi çevresindeki mekânsal dağılımı CBS ortamında bütünleşik olarak ele alınıp mekânsal dağılımları incelenmiştir.

\section{Materyal ve Yöntem}

\section{1. Çalışma Alanı ve Yeri}

Türkiye, tektonik açıdan aktif bir bölgede yer almaktadır. Deprem riski yüksek bölgelerden biri olan İzmit Körfezinde en önemli tektonik yapıyı Kuzey Anadolu Fay Sistemi tanımlar. 
İzmit Kuzey Anadolu Fayı'nın kuzey kolu üzerinde yer almaktadır ve bu yapı bir seri basenlerden oluşmaktadır. İzmit Körfezi'ne boşalan nehirler jeolojik süreç içerisinde Gölcük, Hersek, Kavaklı deltalarını ve Sapanca Gölü ile İzmit Körfezi arasındaki geniş ve uzun alüvyon düzlüğünü oluşturmuştur. Doğu Marmara Körfezi kıyı bölgesi yüzey çökel dağılımında, bölgenin kuzeyinde kıyılar dar bant halinde kum ve çakıllı kum ile kaplıdır.

Kuzey Anadolu Fay Zonu'nun batı bölümünde meydana gelen Marmara depremi Yalova Değirmendere, Gölcük, Karamürsel, İzmit ve Adapazarı başta olmak üzere İstanbul, Bolu ve Düzce'de de etkili olmuştur. 7.5 Mw büyüklüğünde gerçekleşen Kocaeli/Gölcük merkezli deprem ile resmi raporlara göre, 17.118 kişi ölmüş, 50.000 kişi yaralanmıştır (USGS 2005).

17 Ağustos 1999 depremi delta alanında önemli çökmelere neden olmuştur. Ford Otosan yerleşkesinin güneyinden geçen Kavaklı fayı boyunca 2.35 metreye varan düşey atımlar meydana gelmiştir. Ayrıca Gölcük doğu sahilinde çökmeler oluşmuştur. Bu normal faylanmalar alansal bir çökme üretmiş ve Kavaklı sahili yer yer sular altında kalarak, kıyı çizgisinde geniş bir alanda değişmeler olmuştur. Deprem öncesi ve sonrası batimetrik ölçümler kıyı yakınlarının 2 6 metre arasında çöktüğünü göstermektedir. Denize yakın alanlar ve kıyıya yakın yapılar su altında kalmıştır (İTÜ 1999; Barka 2001; Özer vd. 2005; URL1 2016; Aşç1 vd. 2007; Gürsu 2008). Deprem sonucu konutlarda meydana gelen hasar ve yerleşim birimlerine göre hasar durumu AFAD tarafından hazırlanan raporda sunulmuştur (Özmen 2000). Depremi takiben İTÜ, Boğaziçi, Kocaeli Üniversitesi, Ankara Üniversitesi, ODTÜ, Kandilli rasathanesi ve TÜBİTAK ve AFAD'ın yaptıkları çalışmaya göre özellikle Adapazarı, Gölcük ve Yalova'da meydana gelen hasarların başlıca sebebinin zemin problemlerinden kaynaklandığı belirlenmiştir (IÜ 1999; Efe ve Demirci 2001).

Bölgenin, İstanbul, Adapazarı, Gebze, Bursa gibi önemli sanayi merkezlerine yakınlığı, Gebze TEM Otoyolu ve E-5 Karayolu'nun geçtiği kara, deniz ve demiryolunun kesiştiği önemli bir kavşak alanında bulunması, kurulan organize sanayi bölgeleri ve yeni açılan sanayi alanları ile birlikte deprem sonrası nüfus hızla artmaya başlamıştır. Nüfus artışı yapılaşma ve bina yoğunluğuna da yansımıştır. Yapılaşma yoğunluğunun arttığı intersismik dönemde, alüvyal alanlardaki çökme hareketlerinin devam ettiği ve deprem anında sıvılaşma potansiyeli ile birleşerek yıkıcı sonuçlar doğurabildiği görülmüştür. Bu kapsamda sıvılaşma alanlarının mekânsal tespiti ve bina yoğunluk alanlarının sıvılaşma alanları ile entegre değerlendirilmesi oldukça önemlidir.

Şekil 1 İzmit körfezi, körfeze dökülen nehir ağlarını ve körfez çevresi yapı dağılımını göstermektedir. Çalışmada sıvılaşma çalışmalarının alansal dağılım gösterdiği bölgeler ele alınmıştır. Bu kapsamda daha çok körfezin kuzey doğu ve doğu uç bölgelerine odaklanılmıştır. Kocaeli iline ait il-ilçe sınırları haritası (.shp) ve polygon veri türünde bina verileri (.shp) analizler kapsamında ele alınmış olup, binalara ait veri tabanında 2012 yıllarında kayıtlarının yapıldığı tahmin edilen bina kat değerleri kullanılmıştır. Sıvılaşma analizi çalışmalarında, inceleme alanında yer alan 1287 farklı sondaj kuyusuna ait veriler elde edilmiş ve farklı derinlikler için incelemeler yapılmıştır. İnceleme derinliği 0-35 m arası seçilmiştir.

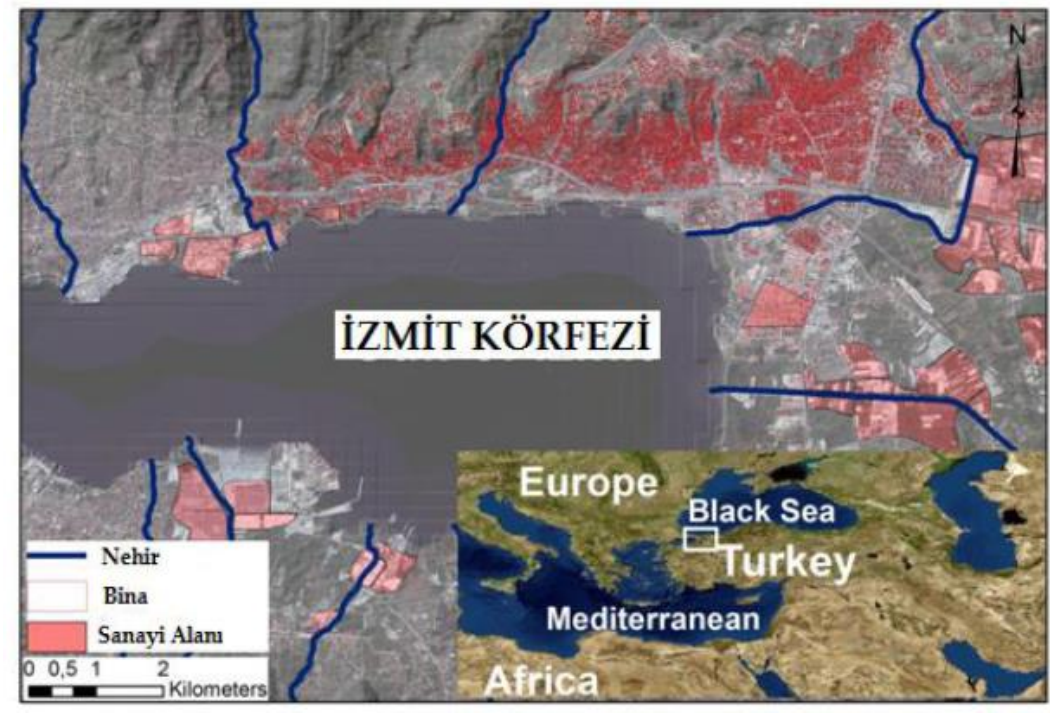

Şekil 1: Çalışma alanı İmit Körfezi, bina ve nehir ağı dağıımı

\subsection{Uygulama}

Bina yoğunluğu kentsel planlama ve arazi yönetimi için oldukça önemli bir kavram olup, bir alandaki bina konsantrasyonu (miktarı) olarak tanımlanmaktadır. İnşa edildiği arazi alanında kullanılan taban alanı miktarı ölçüsüdür. Geleneksel ölçüm ve teknikleri zaman alıcı ve pahalı olduğu için kentsel dağılım, bina yoğunluğu gibi bilimsel çalışmalar haritalama ve görüntülemede CBS ve uzaktan algılama alanına yönlenmiştir (Yang ve Liu 2005; Haack ve Rafter 2006; Xiao 2006; Pan vd. 2008; Jat 2008). 
Çalışma kapsamında bina verileri zemin üstü kat değerlerine ait mekânsal otokorelasyon (SA) analizleri değerlendirilerek verilerin mekânsal deseninin başka bir deyişle mekânsal dağılımının (kümelenme, rastlantısal, dağınık) analizi amaçlanmıştır. Coğrafyanın birinci yasasına göre "her şey diğer her şeyle ilişkilidir, ancak yakın şeyler uzak şeylerden daha ilişkilidir" (Tobler 1970). Birbirine yakın olan alanlar birbirine benziyorsa, SA'nın pozitif olduğu söylenebilir. Negatif SA, benzer olmayan komşu alanlar için geçerlidir ve rastgele desenler SA göstermez (Mitra 2009). SA teknikleri global ve lokal olmak üzere ikiye ayrılır.

Global SA tekniklerinde seçilen örneklemin dağılımına ait tek bir endeks değeri ve tek bir z- istatistik değeri hesaplanır. Moran I endeksi (Moran's I index) ve Geary'nin C oranı (Geary's C ratio) global SA tekniklerindendir. Lokal SA tekniklerinde veriler arasında benzer değişken değerlere sahip olan noktaların oluşturduğu kümelerin konumlarının tespit edilmesi amacıyla noktaların dağılımına ait genel bir değerlendirme yerine nokta verilerinin ayrı ayrı değerlendirilmesi tercih edilir. Bu teknikte örneklemde seçilen her nokta için ayrı ayrı endeks değeri ve z-istatistik değerleri hesaplanır. Getis-Ord G* lokal istatistiği ve Anselin lokal Moran'ın I istatistiği (Getis ve Ord 1992; Moran 1948) lokal SA tekniklerindendir.

Bina nokta verilerine ait değişken değerlerinin (zemin üstündeki kat sayıları) incelenmesi hedeflendiği için bu çalışmada Anselin Lokal Moran'ın I İstatistiği (Cluster and Outlier Analizi) kullanılmıştır. Anselin lokal Moran'ın I istatistiği Formül 1 kullanılarak hesaplanır:

$$
I_{\dot{I}}=\frac{x_{i}-\bar{X}}{S_{i}^{2}} \sum_{j=1, j \neq i}^{n} w_{i, j}\left(x_{j}-\bar{X}\right)
$$

Yukarıda ki formülde; $n$ örneklemdeki nokta sayısı, $\mathrm{w}_{\mathrm{i}, \mathrm{j}}$, i noktası ve j noktası arasındaki yakınlık ilişkisini veren mekânsal ağırlık değeri, $x_{i}$, i noktasındaki değişken değeri, $\bar{x}$, değiş̧kene ait ortalama değeridir.

$$
\begin{gathered}
E\left[I_{i}\right]=-\frac{\sum_{j=1, j \neq 1}^{n} w_{i j}}{n-1} \\
V\left[I_{i}\right]=E\left[I_{i}^{2}\right]-E\left[I_{i}\right]^{2}
\end{gathered}
$$

Bu denklemde; Ii, i noktası için hesaplanan Anselin lokal Moran’ın I istatistik değeri, E(Ii ), i noktası için beklenen Anselin lokal Moran'ın I istatistik değeri, V(Ii ), i noktası için Anselin lokal Moran’ın I istatistiği varyans değeridir.

Anselin lokal Moran'ın I istatistiği z-istatistik değeri tüm noktalar için:

$$
z_{I i}=\frac{I_{i}-E\left[I_{i}\right]}{\sqrt{V\left[I_{i}\right]}}
$$

şeklinde hesaplanır. Verilerin değerlendirme sonuçları istatiksel olarak anlamlı olup olmadıkları hipotez testi ile sınanır.

Sıfır Hipotezi (H0), incelenen noktaya ait değişken değerleri ile bu noktaya yakın noktaların değişken değerleri arasında herhangi bir ilişski yoktur. Alternatif Hipotez (HA), incelenen noktaya ait değişken değerleri ile bu noktaya yakın noktaların değişken değerleri arasında bir ilişki vardır şeklindedir. Sıfır hipotezinin reddedildiği durumda mekânsal dağılımın rastlantısal olmadığı kabul edilir; reddedilmediği durumda ise mekânsal dağılımın rastlantısal olduğu sonucuna ulaşılır. Sıfır hipotezinin belirlenen güven düzeyinde reddedilmesi yani alternatif hipotezinin kabul edilmesi için; $|z i| \geq z \alpha$, koşulunu sağlaması gerekir (z $\alpha$ normal dağılım için $\alpha$ güven düzeyindeki eşik değeridir).

Binalara ait veri tabanında 2012 yıllarında kayıtlarının yapıldığı tahmin edilen bina kat değerleri kullanılmıştır. Mekânsal analizlere başlamadan önce poligon veri türünde bulunan bina verisi nokta verisine dönüştürülmüştür. Nokta verileri ve Kocaeli il-ilçe sınırları haritası birlikte açılarak zemin üstü kat değerleri için çıktı haritaları oluşturulmuştur.

Analizde kullanılan Anselin Lokal Moran's I İstatistiği sonucunda hesaplanan z-istatistik değerlerine göre HH, HL, LH, LL noktaları tespit edilmiştir. HH, istatistiksel olarak anlamlı yüksek değer kümelerini, LL düşük değer kümelerini, HL yüksek bir değerin öncelikle düşük değerlerle çevrili olduğu aykırı değeri, LH düşük değerin yüksek değerlerle çevrili olduğu aykırı değeri tanımlamaktadır.

Şekil 2'ye göre HH değerleri incelendiğinde Darıca, Körfez (doğu kesmi), Derince ve İzmit (Kuzey) ilçeleri için körfez kıyıları, Gölcük kuzey doğu kesiminde yüksek katlı binaların kümelendiği görülmektedir. LL değerleri ise az katlı bina kümelerini göstermekte, daha çok kıyı kesiminden uzak yüksek bölgelerde bu kümeleşmelerin yaygın olduğu izlenmiştir. HL değerleri yüksek bir binanın az katlı binalarla çevrili olduğu aykırı yapıları sunmaktadır. Bașiskele körfez kuzey kesimi ve Kartepe kuzey batı kesimlerinde bu kümelenmelere rastlamaktadır. 


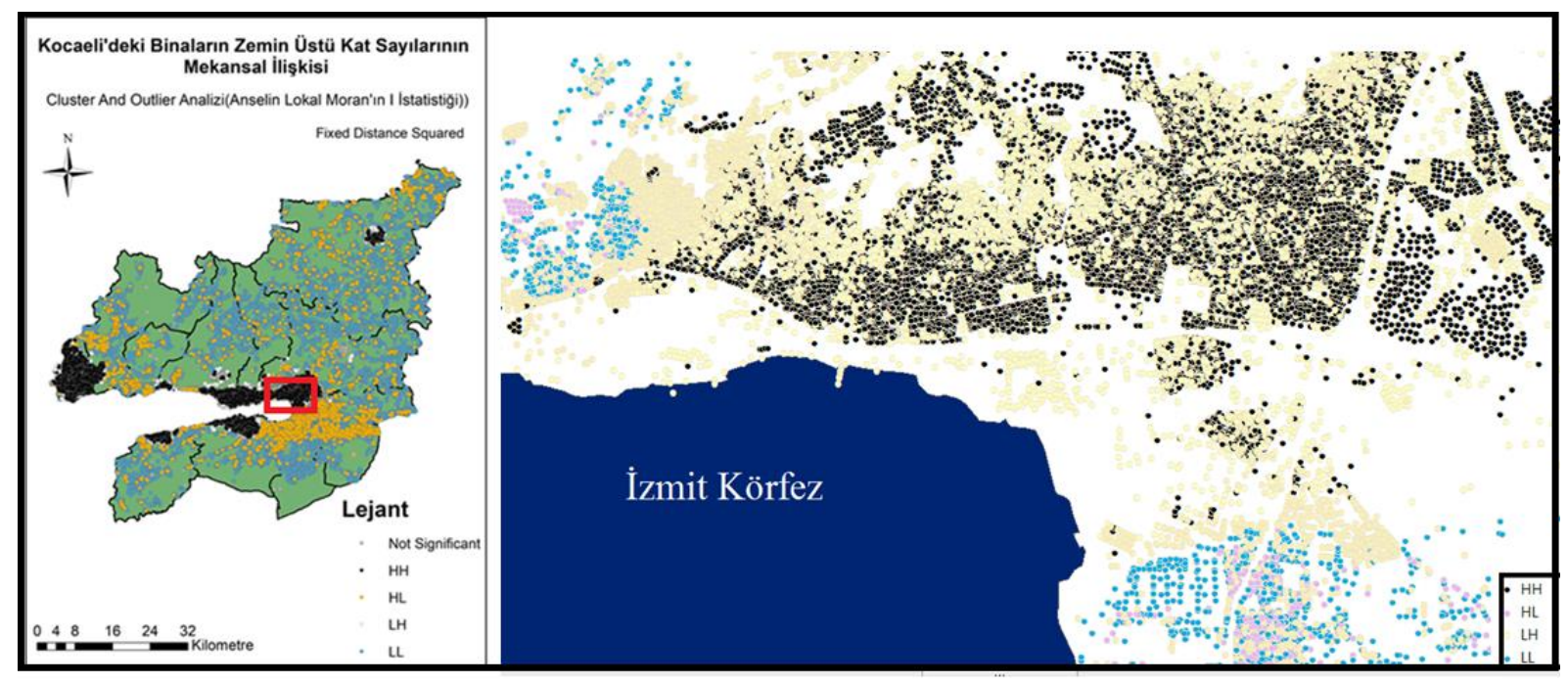

Şekil 2: Bina zemin üstü katları Anselin Lokal Moran's I dağılımları

Sıvılaşma analizi çalışmalarında, inceleme alanında yer alan sondaj kuyusuna ait veriler elde edilmiş ve farklı derinlikler için ölçümler tamamlanmıştır. Ölçümler $0 \mathrm{~m}$ ile $35 \mathrm{~m}$ derinlikleri aralığında yapılmıştır. Yapılan çalışmaya ait akış şeması verilmiştir (Şekil 3). Buna göre önce excel ortamında elde edilen ölçüm değerleri bilgi sistemine atılarak bir veri tabanı oluşturulmuştur. Veri tabanında 0-3 m, 3-6 m, 6-9 m,9-12 m,.., 30-33 m, 33-35 m derinlik alanları için sıvılaşma ölçümleri düzenlenmiş ve ölçüm noktaları koordinat bilgilerine göre mekânsal olarak CBS ortamına aktarılmıştır. Daha sonra ölçülen her bir derinlik aralığı için istasyon ölçüm noktaları etrafında maskeleme için tampon alanı belirlenmiştir. Bu alanın dışında enterpolasyon yapılarak sıvılaşma alanları mekânsal olarak haritalanmıştır. Enterpolasyon için ters ağırlık mesafe (IDW) yöntemi kullanılmıştır. IDW tekniği enterpole edilecek yüzeyde yakındaki noktaların uzaktaki noktalara göre daha fazla ağırlığa sahip olması esasına dayandırılır. Yani, tahmini yapılacak bilinmeyen nokta, komşu civardaki noktaların uzaklığı ve büyüklüğünün bir fonksyonudur. Enterpolasyon için kullanılan örneklem noktalarının, bilinmeyen noktada önem ve etkisi, mesafenin artması ile azalır (Shepard 1968; Lu ve Wong 2008).

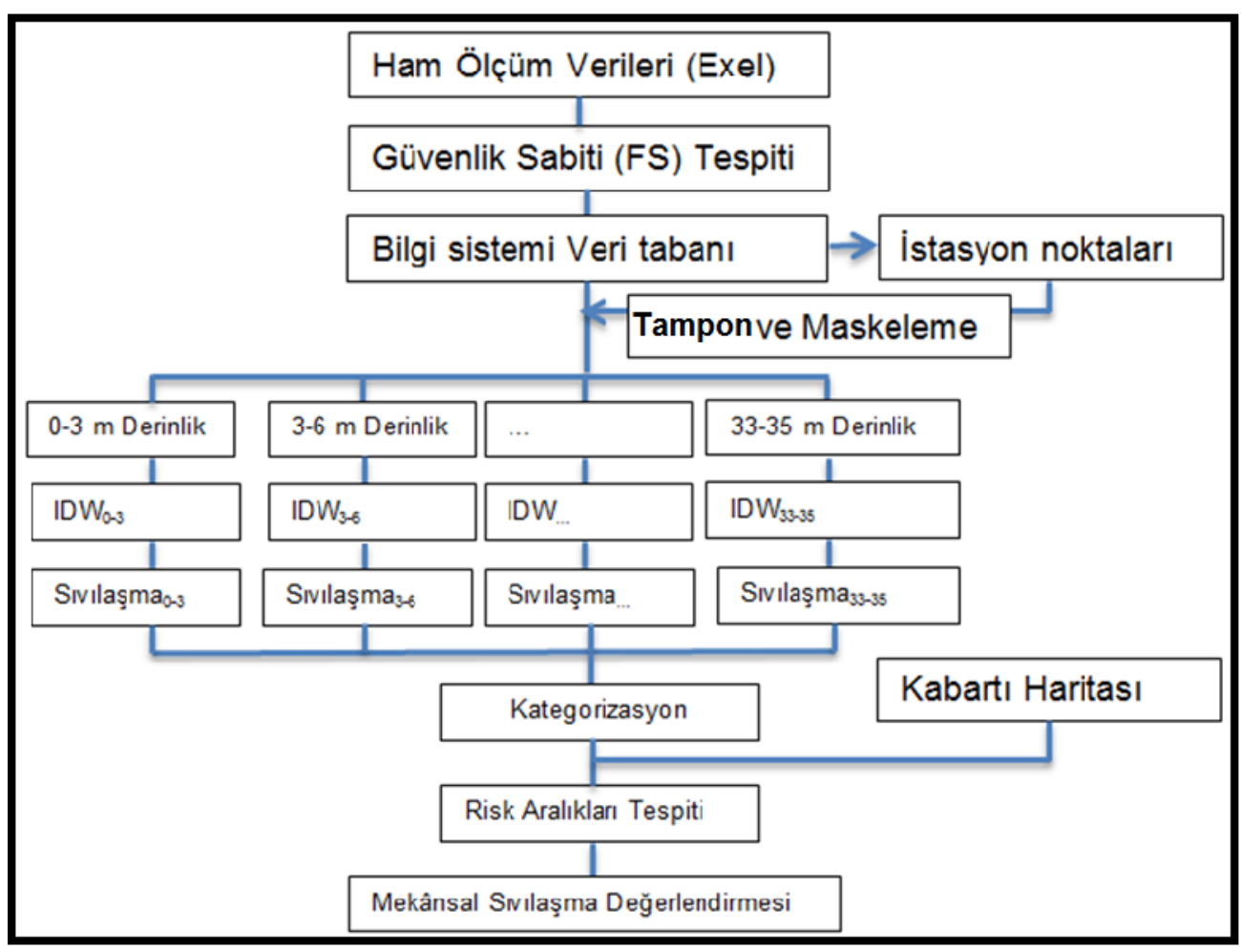

Şekil 3: Sıvılaşma çalışması akış şeması 
Tablo 1: Sıvılaşma potansiyeli risk aralıkları (Sönmez 2003)

\begin{tabular}{ll}
\hline GF $(\mathbf{F S})^{1}$ & SP $(\mathbf{L P})^{\mathbf{2}}$ \\
\hline $\mathrm{FS} \geq 1.2$ & Sıvılaşma Riski Yok \\
$1.2>\mathrm{FS} \geq 1.0$ & Düşük Sıvılaşma Riski \\
$1.0>\mathrm{FS} \geq 0.95$ & Orta Sıvılaşma Riski \\
$0.95>$ FS $\geq 0.85$ & Yüksek Sıvılaşma Riski \\
$>0.85$ & Çok Yüksek Sıvılaşma Riski \\
\hline${ }^{1}$ GF (FS):Güvenlik Faktörü (Factor of safety) \\
${ }^{2}$ SP (LP): Sivılaşma Potansiyeli (Liquefaction potential)
\end{tabular}

Çalışma sonunda 13 farklı derinlik alanı için geçerli sıvılaşma haritaları oluşturulmuştur. Güvenlik Faktörü (FS) değerleri Shuvankar vd. (2018) ve Sönmez (2003)'e göre tanımlanan sıvilaşma potansiyel eşiklerine göre kategorize edilerek sıvılaşma alanları tanımlanmıştır. Sıvılaşma potansiyel eşik değerleri Tablo 1'de sunulmuştur. Buna göre değer aralıkları sıvılaşma potansiyeline ve güvenlik faktörüne göre 5 farklı kategoriye ayrılmıştır. Her derinlik aralığı için kullanılan istasyon kuyuları dağılımları 2.5 boyutlu topoğrafya üzerine oturtularak risk haritaları oluşturulmuştur (Şekil 4).

Çalışma sonunda elde edilen sıvılaşma haritaları değerlendirildiğinde 9 m'ye kadar olan derinlik bölgelerinde sıvılaşmaların gözlendiği, fakat 9 m'den büyük derinlikler için sıvılaşma alanlarının bulunmadığı gözlenmiştir. Bu nedenle gözlemlenen sıvılaşma alanları farklı derinlikler için Şekil 4'de sunulmuştur. İnceleme alanındaki bina temellerinin oturduğu zeminlerde meydana gelen basınç soğanları dikkate alınarak sıvılaşma analizleri bu derinliklere göre yapılmıştır. Basınç soğanı derinliği temel tipi ve kat adedine göre değişmektedir. Bu derinlikler dışında zemin üzerine gelen yükleri güvenle taşıyabilmektedir. Bu derinliklerin içinde kalan bölgelerde ise zemin emniyet gerilmesi aşılacağından temel zemini üzerindeki binalar için risk taşıyacaktır (Ardıç 2006). İnceleme alanındaki zeminlerin gözenekliği yüksek olduğundan bina yoğunluğunun yüksek olduğu alanlarda bölgesel anlamda da zemin yenilmeleri oluşabilecektir.

0-3 m derinlik için elde edilen güvenlik katsayısı değerleri 0.25 ile 6.14 aralığında değişim göstermektedir. Etki alanı diğer derinliklere göre daha yaygın ve büyüktür. İzmit ilçesinde; Körfez kıyı kuzey doğu uç Körfez, Karabaş ve Kozlukkemalpaşa mahallelerinde ayrica Alikahya Cumhuriyet, Alikahya Fatih ve Alikahya Atatürk mahallelerinde yüksek riskli ve riskli bölgeler gözlenmiştir (Şekil 4). Körfez kıyı doğu bölgesinde Sanayi mahallesinde, ayrıca Gölcük ilçesi güney bölgede Sahil, Sepetlipınar ve Yazlıkyeni mahallelerinde riskli alanlar tespit edilmiştir. 3-6 m ve 6-9 m derinlik için güvenlik katsayısı değerleri sırası ile 0.37 ile 10.72 ve 0.55-16.84 aralığında değişmektedir. 3-6 m derinlik için Körfez kıyı kuzey doğu uç bölgesinde, Körfez ve Kozluk Kemalpaşa mahallelerinde ayrıca daha kuzey iç kesimlerde ise Alikahya Cumhuriyet mahallesinde riskli alanlar gözlenmiştir. 6-9 m derinlikte ise kuzey iç kesimlerde Alikahya Cumhuriyet mahallesinde riskli alanlar gözlenmiştir.

Sıvılaşma alanları daha yaygın olarak 0-3 m derinliklerde gözlendiği için, bu derinlik için oluşturulan risk haritası bina envanteri ile örtüştürülmüştür. Bina envanterinde bulunan 115574 bina, değerlendirme alanına düşmektedir. Sivılaşma riski çok yüksek (0.20-0.85), yüksek (0.85-0.95), orta (0.95-1), düşük (1-1.2) ve risksiz (1.2 ve üstü) bölgeler için bina sorgulamaları yapılmış ve risk altında bulunan alanlardaki binalar ve kat oranları tespit edilmiştir. Yapılan sorgulamalardan elde edilen sonuçlar Tablo 2'de sunulmuştur. 

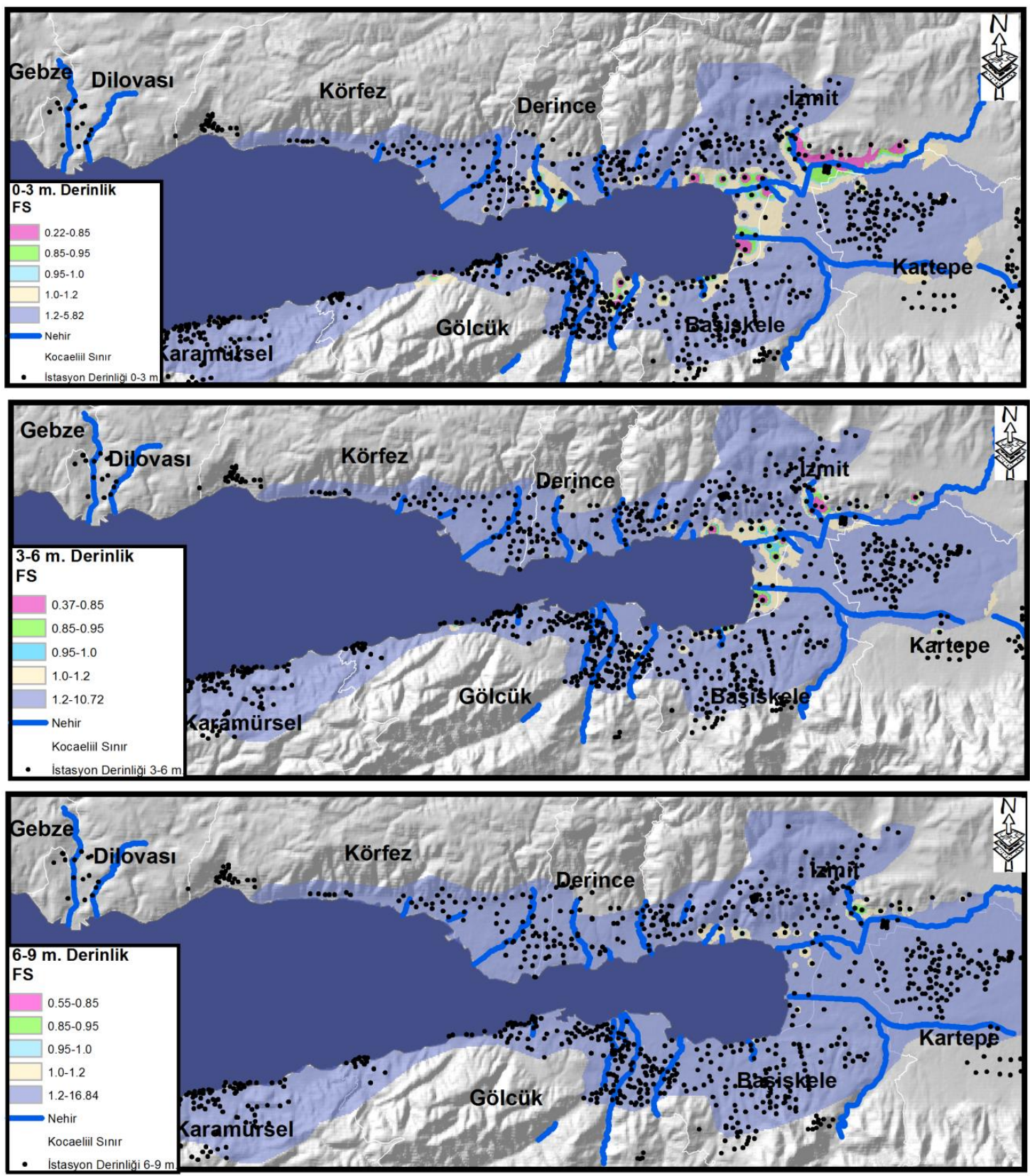

Şekil 4: 0-3, 3-6 ve 6-9 m derinlikler alanlarında sıvılaşma riski haritaları (AsterGDEM verisinden üretilen kabartı harita üzerine bindirilmiştir) 
Tablo 2: Sıvılaşma risk aralıkları ve bina örtüşmeleri

\begin{tabular}{cccccc}
\hline $\begin{array}{c}\text { Sıvılaşma Risk aralığı } \\
\mathbf{0 - 3} \mathbf{~ m}\end{array}$ & $\begin{array}{c}\text { Alan } \\
\left(\mathbf{h m}^{2}\right)\end{array}$ & Toplam bina sayısı & Kat aralığı & $\begin{array}{c}\mathbf{5} \text { kat ve altı } \\
\text { bina sayısı }\end{array}$ & $\begin{array}{c}\mathbf{6} \text { kat ve üstü } \\
\text { bina sayısı }\end{array}$ \\
\hline $0.20-0.85$ (Yüksek Riskli) & 74.73 & $2836(\% 2.43)$ & $1-17$ & 2698 & 138 \\
$0.85-0.95$ (Riskli) & 106.54 & $2161(\% 1.76)$ & $1-11$ & 2006 & 155 \\
$0.95-1$ (Orta Riskli) & 89.03 & $1704(\% 1.30)$ & $1-11$ & 1551 & 153 \\
$1-1.2$ (Düşük Riskli) & 407.53 & $12784(\% 10.54)$ & $1-15$ & 12061 & 723 \\
1.2 ve üstü (Risksiz) & 1915.31 & $98049(\% 83.97)$ & $1-15$ & 95455 & 2594 \\
\hline
\end{tabular}
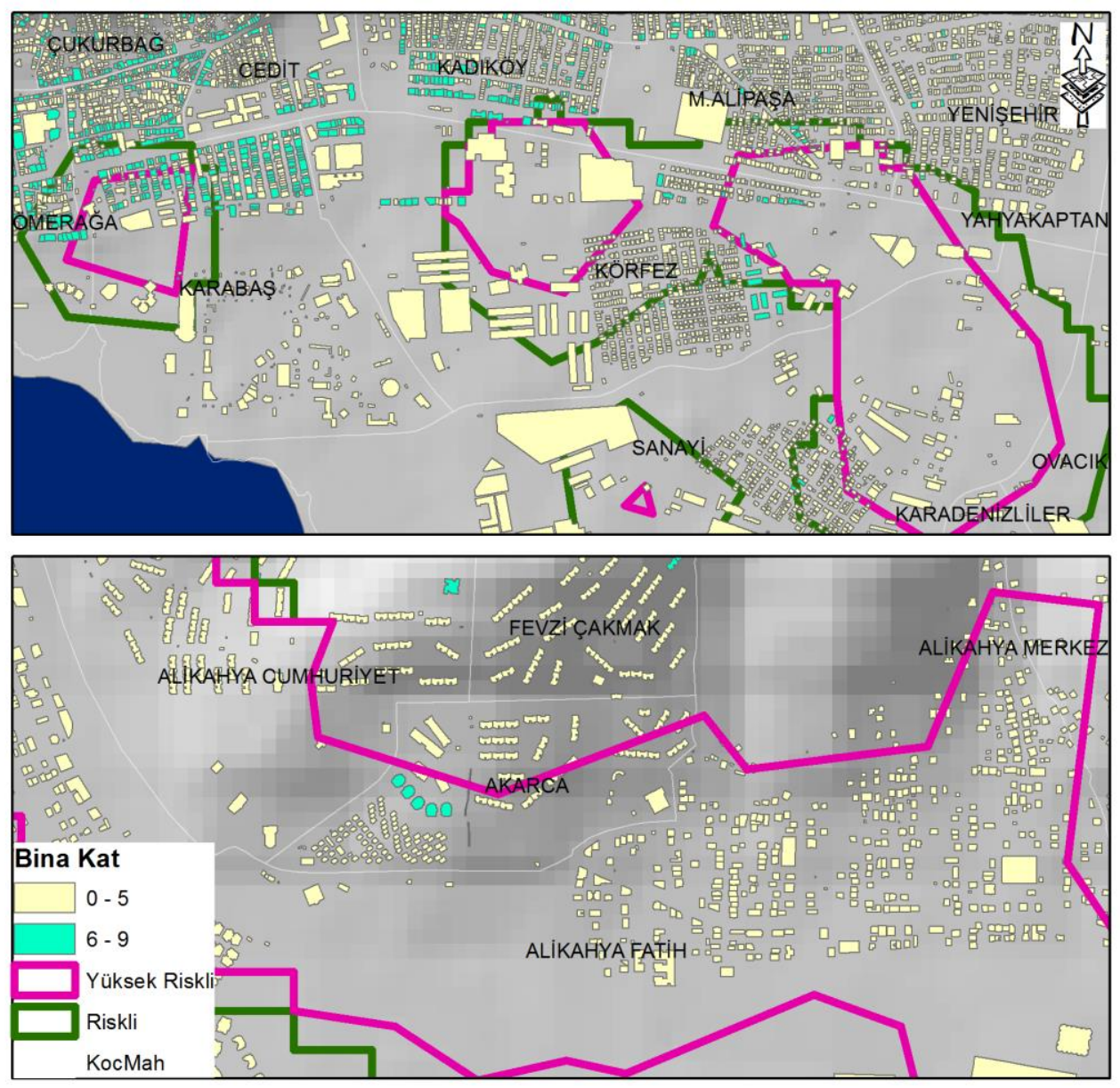

Şekil 5: Sıvılaşma riski bulunan alanlar ile bina kat dağııımları

0-3 m derinlik için, çok yüksek sıvılaşma riskine sahip alanlar ile bina envanteri örtüştürüldüğünde \%4.19 bina yüksek riskli ve riskli bölge içine düşmektedir. 2836 (\%2.43) binanın çok yüksek sıvılaşma riski bulunan alana girdiği gözlenmiştir (Tablo 2). Bu binalar mesken, kamu, işyeri türündedir. Kat yüksekliği 1 ile 17 arasında değişmektedir. Yaklaşık 138 bina 6 kat ve üstü yüksekliğine sahiptir. Riskli alanlara düşen 2161 (\%1.76) bina bulunmakta olup, yaklaşık 155'i, 6 kat ve üstü yüksekliğine sahiptir. Bu bölgede kat yükseklikleri 1 ile 11 arasında değişmektedir. Orta riskli bölge içine 1704 bina düşmektedir. Bu binalar 1 ile 11 kat arasında değişim göstermekte olup, 723 'ü 6 kat ve üstü yüksekliğe sahiptir. Çalışma alanı içine düşen binaların \%94.51'i ise düşük riskli ve risksiz alanlardadır. Yüksek riskli ve riskli sıvılaşma alanı içine düşen binalar ve kat dağılımları Körfez bölgesi ve Alikahya bölgesi için Şekil 5'de sunulmuştur. Bu alanlar için ağırlıklı olarak 5 kat ve altı binaların alanda dağılım gösterdiği gözlemlenmiştir. Ayrıca riskli alanlarda bina yoğunluğunun genelde düşük seyrettiği, iş yeri türünde büyük yapılar yanında, mesken tanımlanan orta ve küçük yapılaşmaların dağılım gösterdiği gözlemlenmiştir. 


\section{Sonuç}

Binalar yer deformasyonundan kaynaklı hareketlere duyarlıdır. Bu nedenle sıvılaşmadan kaynaklı zemin davranışının ve üzerinde bulunan yapı bloklarının mekânsal olarak haritalanması ve gözlemlenmesi bina riskinin önceden tahmini için gereklidir. Bu bağlamda TÜBİTAK tarafından desteklenen bu çalışma kapsamında, bina yoğunluk analizleri ve sıvılaşmanın körfez bölgesi çevresindeki mekânsal dağılımı CBS ortamında bütünleşik olarak ele alınarak mekânsal dağılımları incelenmiştir. Binanın zemine uyguladığı yük, bina yoğunluk haritalamaları ile alansal değişimler olarak tanımlanabilir. Zemindeki yüke ait bilgi çıkarımı için binaların 3. boyutu dikkate alınarak bina katlarının mekânsal dağılımları mekânsal korelasyon çalışmaları ile irdelenmiştir. Mekansal korelasyon analizlerinden Lokal Moran's I istatistikleri dikkate alınmıştır. Anselin Lokal Moran'ın I İstatistiği sonucunda HH değerleri incelendiğinde Darıca, Körfez (doğu kesmi), Derince ve İzmit (Kuzey) ilçeleri için körfezin kuzey kıyıları, Gölcük kuzey doğu kesiminde yüksek katlı binaların kümelendiği görülmektedir. LL değerleri ise az katlı bina kümelerini göstermekte olup, daha çok kıyı kesiminden yüksek olan bölgelerde bu kümeleşmelerin yaygın olduğu izlenmiştir. Ayrıca körfez ve çevresinde görülen sıvılaşma potansiyeli 0-3 m, 3-6 m, 6-9 m, 9-12 m’ den 33-35 m derinlikleri için oluşturulmuştur. Sıvılaşma potansiyel eşiklerine göre, farklı derinlikler için, sıvılaşma değerleri kategorize edilerek sıvılaşma alanları ve riskli bölgeler tanımlanmıştır. 0-3 m derinlikli alanlarda ise çalışma odağı olan körfez kıyı alanlarında sıvılaşma riski gözlendiği için bu risk alanları dikkate alınarak yapılaşma ve sıvılaşma dağılımı örtüştürülerek değerlendirilmiştir. 0-3 m derinlik için, çok yüksek sıvılaşma riskli alanlar ile bina envanteri örtüştürüldüğünde \% 4.19 bina yüksek riskli ve riskli bölge içine düşmektedir. 2836 (\%2.43) binanın çok yüksek sıvılaşma riski bulunan alana girdiği gözlenmiştir. Bu binalar mesken, kamu, işyeri türündedir. Kat yüksekliği 1 ile 17 arasında değişmektedir. Yaklaşık 138 bina 6 kat ve üstü yüksekliğine sahiptir. Riskli alanlara düşen 2161 (\%1.76) bina bulunmakta olup, yaklaşık 155'i, 6 kat ve üstü yüksekliğine sahiptir. Bu bölgede kat yükseklikleri 1 ile 11 arasında değişmektedir. Orta riskli bölge içine 1704 bina düşmektedir. Bu binalar 1 ile 11 kat arasında değişim göstermekte olup, 723'ü 6 kat ve üstü yüksekliğine sahiptir. Çalışma alanı içine düşen binaların \%94.51'i ise düşük riskli ve risksiz alanlara düşmektedir. Bu çalışma kapsamında binanın zemine verdiği yük değerlendirilirken, mevcut veri tabanında bulunan bina kat adedi dikkate alınmıştır yalnız, bina kat adedi yanında bina temel tipi de dikkate alınmalıdır. Gelecek çalışmalarda bina temel tipi veri tabanı da dikkate alınarak, zeminde oluşacak yük değeri incelemesi tavsiye edilmektedir. Ayrıca 0-3 m ve 3-6 m derinliklerdeki sıvılaşma alanları gelecek çalışmalarda entegre olarak bir arada değerlendirilerek 0-6 m de yüksek sıvılaşma riske sahip alanların tespiti ve bu alanlardaki bina tiplerine ve katlarına göre risklerin belirlenmesi planlanmaktadır. Sonuç olarak, binalar ne kadar sağlam ne kadar kaliteli malzemelerle yapılsın; zeminlerin gözenekliği yüksek olan bir alanda, zemin yenilmeleri oluşabilecek, deprem riski yüksek alanlar için yapılar insanlar için büyük risk oluşturabilecektir.

\section{Teşekkür}

Bu çalışma 177155 nolu “Çok Bandlı InSAR ve GNSS Tekniği ile Doğu Marmara (İzmit Körfezi) Düşey Yönlü Yer Değiştirmelerin İzlenmesi, Zemin Çökmeleri ile Bina Yoğunluğu ve Sıvılaşma İlişkisinin Araştırılması” başlıklı TÜBİTAK 1001 projesi kapsamında, Türkiye Bilimsel ve Teknolojik Araştırma Kurumu (TÜBİTAK) tarafından desteklenmektedir. Proje 2017 yılı Aralık ayından itibaren başlamış olup, Kocaeli Büyük şehir Belediyesi ile işbirliği yapılmış ve KOÜ Harita Mühendisliği Bölümü tarafından yürütülmektedir.

\section{Kaynaklar}

Anastasopoulos I., Gazetas G., (2007), Foundation-structure systems over a rupturing normal fault: Part I. observations after the Kocaeli 1999 earthquake, Bulletin of Earthquake Engineering, 5, 253-275.

Ardıç Ö., (2006), Analysis of Bearing Capacity Using Discrete Element Method, Yüksek Lisans Tezi, Orta Doğu Teknik Üniversitesi, Fen Bilimleri Enstitüsü, Ankara.

Arel E., Önalp A., (2012), Geotechnical properties of Adapazı Silt, Bulletin of Engineering Geology and the Environment, 71(4), 709-720.

Aşc1 M., Özçep F., Alpaslan N., Karabulut, S., Yas T., (2003), Evaluation of liquefaction potantial by different approaches in some points of northern part of Gölcük, Turkey, The 3rd International Conference on Earth Sciences and Electronics, Proceedings, October 23-24, İstanbul, Turkey.

Aşçı M., Yas T., Çaka D., Erdoğan B., Özçep F., (2007), Kocaeli-Gölcük Çökme Bölgesi Zemininin Stvılaşma Potansiyeli, International Earthquake Symposium, October 22-26, Kocaeli.

Aşc1 M., Özçep F., Erhan A., Yas T., Alpaslan N., (2007), Liquefaction Potantial of İzmit-Saraybahçe Soils, The 16th International Geophysical Congres and Exhibition of Turkey, December 07-10, Ankara.

Aydan Ö., Ulusay R., Atak V.O., (2008), Evaluation of ground deformations induced by the 1999 Kocaeli earthquake (Turkey) at selected sites on shoreline, Environ Geol, 54(165), doi:10.1007/s00254-007-0803-x.

Barka A., (1999) The 17 August 1999 Izmit Earthquake, Science, 285, 1858-1859.

Barka A., (2001), 17 Ağustos 1999 İzmit Depremi Postsismik Deformasyonun Sentetik Açıklık Radar İnterferometrisi Yöntemi ile İncelenmesi, Yüksek Lisans Tezi, İstanbul Teknik Üniversitesi, Avrasya Yer Bilimleri Enstitüsü, İstanbul. 
Bray J.D., Sancio R.B., Riemer M.F., Durgunoglu H.T., (2004), Liquefaction susceptibility of fine-grained soils, Editör: Doolin, Kammerer, Nogami, Seed, Towhata, Proc. 11th Inter. Conf. On Soil Dynamics and Earthquake Engineering and 3rd Inter. Conf. on Earthquake Geotechnical Engineering 1, Jan. 7-9, Stallion Press, Berkeley, California, USA.

Bray J.D., Dashti S., (2014), Liquefaction-Induced Building Movements, Bulletin of Earthquake Engineering, 12(3), $1129-1156$.

Bray J.D., Macedo J., (2017), 6th Ishihara lecture: Simplifed procedure for estimating liquefaction induced building settlement, Soil Dynamics and Earthquake Engineering, 102, 2015-231.

Çetin K.Ö., Unutmaz B., (2004), Zemin sıvılaşması ve sismik zemin davranışı, Türkiye Mühendislik Haberleri (TMH), 430-2004/2, 32-37.

Demirtaş R., (1999), 17 Ağustos 1999 İzmit Körfezi Depremi; Hasarın Ağır Olmasında Ne Etkili Oldu?”. Haber Bülteni, http://eski.jmo.org.tr/resimler/ekler/9dfa2df42d9e3d4_ek.pdf?dergi=HABERBULTENI [Erişim 02 Ocak 2020].

Demirtaş R., (2000), 17 A ğustos 1999 İzmit Körfezi Depremi Raporu, Deprem Araştırma Dairesi Başkanlığı, Ankara, $295 \mathrm{ss}$.

Demirtaş R., Şaffak D., Şahin M., Bulut N., (2008), Kavaklı Fayı (Gölcük-Izmıt) Paleosismisite Arastırmaları, http://www.academia.edu/8775512/Kavakl1_Fay1_Golcukİzmit_Paleosismisite_Arastırmalar1_Yuzey_Faylanmas1_Tehlıke_Zonu Acısından_Degerlendirme, [Erişim 02 Ocak 2020].

Efe $\bar{R} .$, (2000), Gölcük ve Düzce Depremleri 1999, Fatih Üniversitesi Yayınları, No.7, İstanbul, 134ss.

Efe R., Demirci A., (2001), Gölcük 1999 depreminde zemin ve yerşekli özelliklerinin şiddet ile hasar dağıllşına etkisi, Türk Coğrafya Dergisi, 36, 1-15 .

Erdik M., Demircioğlu M.B., Sesetyan K., Durukal E., Siyahi B., (2004), Earthquake Hazard in Marmara Region, Soil Dynamics And Earthquake Engineering, 24, 605-631.

Erken A., Özay R., Kaya Z., Ülker M.B.C., Elibol B., (2004), Depremler Sırasında Zeminlerin Sıvılaşması ve Taşıma Gücü Kayıplarl, Türkiye Mühendislik Haberleri, Sayı 431- 2004/3, 20-26.

Getis A., Ord J.K., (1992), The analysis of spatial association by Use of distance statistics, Geographical Analysis, 24, 189-206.

Gürsu, (2008), Kocaeli Illi Yazlık-Hisareyn-İhsaniye-Yeniköy ve Gölcük sinırları içinde kalan Afete Maruz Bölge’nin Revize İmar Planına Esas Jeolojik-Jeoteknik Etüt Raporu, Sismik Zemin Mühendislik Ltd. Şti., Kocaeli.

Haack B.N., Rafter A., (2006), Urban growth analysis and modelling in the Kathmandu valley, Nepal, Habitat International, 30(4), $1056-1065$.

Idriss I.M., Boulanger R.W., (2006), Semi-empirical procedures for evaluating liquefaction potential during earthquakes, 11th International Conference on Soil Dynamics and Earthquake Engineering (ICSDEE): Part II 26, 115-130.

Idriss I.M., Boulanger R.W., (2008), Soil liquefaction during earthquakes monograph mno-12, Earthquake Engineering Research Institute, Oakland, CA, 261ss.

Ishihara K., Yoshimine M., (1992), Evaluation of settlements in sand deposits following liquefaction during earthquakes, Soils Found 32(1), 173-188.

IÜ, (1999), 17 A ğustos 1999 Gölcük (Kocaeli) depremi, İstanbul Üniversitesi Raporu, http://avnidincer.8m.com/IURapor.html [Erişim 02 Ocak 2017].

Iwasaki T, Tokida K, Tatsuoka F, Watanabe S, Yasuda S, Sato H, (1982), Microzonation for soil liquefaction potential using simplified methods, The 3rd International Conference on Microzonation, Seattle, ss.1310-1330.

İTÜ, (1999), İstanbul Teknik Üniversitesi Ön değerlendirme Raporu, 17 Ağustos 1999 Kocaeli Depremi, http://web.archive.org/ web/20120611004336/http://www.belgenet.com/deprem/depremitu.html [Erişim 27 Aralık 2016].

Jat M.K., Garg P.K., Khare D., (2008), Monitoring and modelling of urban sprawl using remote sensing and GIS techniques, International Journal of Applied Earth Observation and Geoinformation, 10, $26-43$.

Lu G.Y., Wong D.W., (2008). An adaptive inverse-distance weighting spatial interpolation technique, Computers \& Geosciences, 34(9), 1044-1055.

Mitra D.L., (2009), Strengthening student voice initiatives in high schools: An examination of the supports needed for school-based youth-adult partnerships, Youth \& Society, 40(3), 311-335.

Moran P., (1948), The interpretation of statistical maps, Journal of the Royal Statistical Society, 10, 243-251.

Pan X.Z., Zhao Q.G., Chen J., Liang Y., Sun B. (2008), Analyzing the Variation of Building Density Using High Spatial Resolution Satellite Images: The Example of Shanghai City, Sensors, 8(4), 2541-2550.

Saygılı G., Hanna A.M., Ural D., (2007), Neural network model for liquefaction potential in soil deposits using Turkey and Taiwan earthquake data, Soil Dynamics and Earthquake Engineering, 27, 521-540.

Özmen B., (2000), 17 Ağustos 1999 İzmit Körfezi Depreminin Hasar Durumu (Rakamsal Verilerle), Türkiye Deprem Vakfi, TDV/DR 010-53, http://deprem.gazi.edu.tr/posts/download?id=43388, [Erişim 2 Ocak 2017].

Seed H.B., Idriss I.M., (1971), Simplified procedure for evaluating soil liquefaction potential, Journal of Soil Mechanicsand Foundation Division, 97(9), doi: 10.1061/JSFEAQ.0001662.

Seed H.B., Tokimatsu K., Harder L.F., Chung R.M., (1985), Influence of SPT Procedures in Soil Procedures in Soil Liquefaction Resistance Evaluations, Journal of Geotechnical Engineering, 111(12), 1425-1445.

Shepard D., (1968), A two-dimensional interpolation function for irregularly-spaced data, Proceedings of the 1968 ACM National Conference, ss.517-524.

Shuvankar D., Sima G., Kayal J.R., (2018), Liquefaction Potential of Agartala City in Northeast India Using a GIS Platform, Bulletin of Engineering Geology and the Environment, (2019)78, 2919-2931

Sönmez H., (2003), Modification of the liquefaction potential index and liquefaction susceptibility mapping for a liquefaction-prone area (Inegol, Turkey), Environmental Geology, 44, 862-871.

Ulusay R., Aydan Ö., Kumsar H., Sönmez H., Tuncay E., (2000), Türkiye'de Son Depremlerde görülen sivılaşma olgusu ve Batı Anadolu'da slvılaşma potansiyeline genel bir bakış, Batı Anadolu'nun Depremselliği Sempozyumu, 24-27 Mayıs, İzmir, ss.323336.

URL-1, (2016), http://www.ym.com.tr/Files/UserFiles/Arge/Deprem_Muhendisligi/6.\%20Dogu\%20marmara\%20depremi.pdf, [Erişim 27 Aralık 2016]. 
USGS (2005), M7.6 - 4 km ESE of Derince, Turkey, https://earthquake.usgs.gov/earthquakes/eventpage/usp0009d4z/executive [Erişim 23 Ekim 2021].

Xiao J., Shen Y., Ge J., Tateishi R., Tang C., Liang Y., Huang Z., (2006), Evaluating urban expansion and land use change in Shijiazhuang, China, by using GIS and remote sensing, Landscape and Urban Planning, 75, 69-80.

Yüksel Y., Özmen H., Çevik E., Özgüven O., Çelikoğlu Y., Bostan T., Gürer S., Gökoğlu F., (2000), Doğu Marmara Depreminin Körfez Bölgesi Deniz Yapıları Üzerindeki Etkileri, III. Ulusal Kıyı Mühendisliği Sempozyumu, 5-7 Ekim, Çanakkale.

Yang X., Liu Z., (2005), Use of satellite derived landscape imperviousness index to characterize urban spatial growth, Computers, Environment and Urban Systems, 29, 524-540. 